\title{
Physical and chemical characterization of biochars derived from different agricultural residues
}

\author{
K. Jindo ${ }^{1,2}$, H. Mizumoto ${ }^{3}$, Y. Sawada ${ }^{2}$, M. A. Sanchez-Monedero ${ }^{1}$, and T. Sonoki ${ }^{3}$ \\ ${ }^{1}$ Centro de Edafología y Biología Aplicada del Segura (CEBAS-CSIC), Department of Soil Conservation and Waste \\ Management, Campus Universitario de Espinardo, 30100 Murcia, Spain \\ ${ }^{2}$ Institute of Industrial Science, the University of Tokyo, 3-8-1 Komaba, Meguro-ku, Tokyo 153-8902, Japan \\ ${ }^{3}$ Faculty of Agriculture and Life-Sciences, Hirosaki University, Bunkyo-cho, Hirosaki, Aomori 036-8561, Japan \\ Correspondence to: K. Jindo (keijindo@ hotmail.com)
}

Received: 10 July 2014 - Published in Biogeosciences Discuss.: 1 August 2014

Revised: 23 October 2014 - Accepted: 1 November 2014 - Published: 1 December 2014

\begin{abstract}
Biochar is widely recognized as an efficient tool for carbon sequestration and soil fertility. The understanding of its chemical and physical properties, which are strongly related to the type of the initial material used and pyrolysis conditions, is crucial to identify the most suitable application of biochar in soil. A selection of organic wastes with different characteristics (e.g., rice husk $(\mathrm{RH})$, rice straw (RS), wood chips of apple tree (Malus pumila) (AB), and oak tree (Quercus serrata) $(\mathrm{OB})$ ) were pyrolyzed at different temperatures $\left(400,500,600,700\right.$, and $\left.800^{\circ} \mathrm{C}\right)$ in order to optimize the physicochemical properties of biochar as a soil amendment. Low-temperature pyrolysis produced high biochar yields; in contrast, high-temperature pyrolysis led to biochars with a high $\mathrm{C}$ content, large surface area, and high adsorption characteristics. Biochar obtained at $600^{\circ} \mathrm{C}$ leads to a high recalcitrant character, whereas that obtained at $400^{\circ} \mathrm{C}$ retains volatile and easily labile compounds. The biochar obtained from rice materials (RH and RS) showed a high yield and unique chemical properties because of the incorporation of silica elements into its chemical structure. The biochar obtained from wood materials (AB and $\mathrm{OB}$ ) showed high carbon content and a high absorption character.
\end{abstract}

\section{Introduction}

The interest in the application of biochar as a method for mitigating the global-warming effects is steadily increasing. In addition to the studies on the use of biochar for carbon sequestration, a number of reports have focused on alterna- tive applications of biochar for the improvement of soil fertility, plant growth, and decontamination of pollutants such as pesticides, heavy metals, and hydrocarbons (Beesley et al., 2011; Cabrera et al., 2011). The diverse range of biochar applications depends on its physicochemical properties, which are governed by the pyrolysis conditions (heating temperature and duration) and the original feedstock (Enders et al., 2012). Thus, detailed information about the complete production process is a key factor in defining the most suitable application of biochars.

The biochar physicochemical properties can cause changes in the soil nutrient and $\mathrm{C}$ availability, and provide physical protection to microorganisms against predators and desiccation; this may alter the microbial diversity and taxonomy of the soil (Lehman et al., 2011). The biochar derived from relatively low-temperature pyrolysis is characterized by a high content of volatile matter that contains easily decomposable substrates, which can support plant growth (Robertson et al., 2012; Mukherjee and Zimmerman, 2013). In contrast, the structure of biochar derived from hightemperature pyrolysis is characterized by a large surface area and aromatic-carbon content, which may increase the adsorption capacity (a desirable property for bioremediation) as well as the recalcitrant character (for carbon sequestration) (Lehmann, 2007).

The type of feedstock material is another important factor that determines the final application of the biochar and its effect in soil, because its properties are affected by the nature of the original material. For instance, the soil cationexchange capacity of manure-based biochars is higher than 
that of wood (Eucalyptus) biochar (Singh et al., 2010), while the treatment of soil with woodchip biochar results in higher saturated hydraulic conductivities than that treated with manure-based biochar (Lei and Zhang, 2012).

The aim of our study is to optimize the physicochemical characteristics of biochar for its use in agriculture by investigating different pyrolysis conditions and agricultural wastes used as feedstocks. To achieve this aim, the thermochemical properties of the biochars obtained at different temperatures $\left(400-800{ }^{\circ} \mathrm{C}\right)$ were evaluated. Rice husk $(\mathrm{RH})$ and rice straw (RS) were used as the starting materials, because the global amount of residues from rice crops (Oryza sativa L.) is $0.9 \mathrm{Gt}$ per year, i.e., $25 \%$ of the total amount of the global agricultural residues (Knoblauch et al, 2011). Pruning woodchips of apple tree (AB) (Malus pumila) was also used as a biochar material because its carbonization is considered as an alternative waste management for the reduction of hazardous materials such as pesticide remnant (Suri and Horio, 2010). Although several studies have been recently proposed the use of biochar derived from orchard prune residues as a soil amendment (Fellet et al., 2011; Alburquerque et al., 2013), reports on the evaluation of the pyrolysis process on this feedstock are scarce. Finally, oak tree (OB) (Quercus serrata) was used as a reference hardwood biochar.

\section{Materials and methods}

\subsection{Biochar preparation from agricultural residues}

The biochars used in this work were obtained from two rice residues (Oryza sativa L.): straw and husk, as well as two woody materials, i.e., a type of broad-leaved tree (Quercus serrate Murray) and apple-wood chips (Malus pumila). All materials were first dried in air and then cut into small pieces (less than $4-5 \mathrm{~cm}$ ); these were then inserted into a ceramic vessel $\left(370 \mathrm{~cm}^{3}\right)$ that was used in a commercial electric furnace (SOMO-01 Isuzu, Japan). This was charred for $10 \mathrm{~h}$ at different temperatures (from 400 to $800^{\circ} \mathrm{C}$ ) at a heating rate of $10^{\circ} \mathrm{C} \mathrm{min}-1$.

\subsection{Biochar chemical analysis}

After the pyrolysis process, all samples were ground and sieved to less than $0.5 \mathrm{~mm}$ in diameter. The biochar yield was calculated as the proportion of the weight of pyrolysis product to the original material. The determination of the volatile matter and ash content was conducted according to the American Society for Testing and Materials (ASTM) D1752-84, which is recommended by the International Biochar Initiative. The volatile matter was thus determined by measuring the weight loss that follows the combustion of about $1 \mathrm{~g}$ of charcoal in a crucible at $950^{\circ} \mathrm{C}$. Following the same procedure, the ash content was determined at $750^{\circ} \mathrm{C}$. The $\mathrm{pH}$ of each mixture $(1: 10, w / v$ ratio) was measured with the MP220 pH meter. Micro- and mesoporosity were eval- uated with regard to $I_{2}$ and methylene blue (MB) adsorption capacity, respectively, following a previously proposed methodology (Gaspard et al., 2007). The specific surface area was determined using $\mathrm{N}_{2}$ sorption isotherms run on an automated surface area. The specific surface-area distribution was obtained from the adsorption isotherms, using the Brunauer-Emmett-Teller (BET) method (Zhang et al., 2011).

\subsubsection{Elemental composition}

The elemental composition of $\mathrm{C}, \mathrm{H}$, and $\mathrm{N}$ was determined using an elemental analyzer (Thermo Finnigan EA-1112, Thermo Fisher Scientific Inc., MA, USA); the O content was determined by Vario El cube, Elementar Analysensysteme $\mathrm{GmbH}$.

\subsubsection{Thermal analysis}

The thermal analysis of the biochars was performed by using an SDT-2960 simultaneous DSC-TGA thermal analyzer (TA instruments) under static-air atmosphere with the following temperature ramp: (1) temperature equilibration at $30^{\circ} \mathrm{C}$, followed by linear heating (at a rate of $5^{\circ} \mathrm{C} \min ^{-1}$ ) from 30 to $105^{\circ} \mathrm{C}$; (2) isotherm for $10 \mathrm{~min}$; (3) and ramping of $5^{\circ} \mathrm{C} \mathrm{min}^{-1}$ from 105 to $680^{\circ} \mathrm{C}$.

\subsubsection{Fourier-transform infrared (FT-IR) spectroscopy}

FT-IR spectroscopy was analysed on a Varian 670-IR (Agilent Technologies Inc., CA) using the pellet technique by mixing $1 \mathrm{mg}$ of dried biochar with $300 \mathrm{mg}$ of pre-dried and pulverized spectroscopic-grade $\mathrm{KBr}$ (from Merck and Co., Whitehouse Station, NJ). The following broad-band assignment was used (Chen and Chen, 2009; Haslinawati et al., 2011; Novak et al., 2010; Peng et al., 2011; Yuan et al., 2011; Wu et al., 2012; Guo and Chen, 2014): 3400 to $3410 \mathrm{~cm}^{-1}, \mathrm{H}$-bonded $\mathrm{O}-\mathrm{H}$ stretching vibrations of hydroxyl groups from alcohols, phenols, and organic acids; 2850 to $2950 \mathrm{~cm}^{-1}, \mathrm{C}-\mathrm{H}$ stretching of alkyl structures; $1620-1650 \mathrm{~cm}^{-1}$, aromatic and olefinic $\mathrm{C}=\mathrm{C}$ vibrations, $\mathrm{C}=\mathrm{O}$ in amide (I), ketone, and quinone groups; 1580 to $1590 \mathrm{~cm}^{-1}, \mathrm{COO}^{-}$asymmetric stretching; $1460 \mathrm{~cm}^{-1}, \mathrm{C}-\mathrm{H}$ deformation of $\mathrm{CH}_{3}$ group; $1280-1270 \mathrm{~cm}^{-1}$, O-H stretching of phenolic compounds; and three bands around 460, 800 , and $1000-1100 \mathrm{~cm}^{-1}$, bending of $\mathrm{Si}-\mathrm{O}$ stretching.

\subsubsection{Solid-state nucleic magnetic resonance (NMR) spectroscopy}

Cross-polarization magic angle spinning (CPMAS) ${ }^{13} \mathrm{C} \mathrm{nu}-$ clear magnetic resonance $\left({ }^{13} \mathrm{C}\right.$-NMR) spectra were acquired from the solid samples with a Varian 300, equipped with a $4 \mathrm{~mm}$ wide bore MAS probe, operating at a ${ }^{13} \mathrm{C}$ resonating frequency of $75.47 \mathrm{MHz}$. The assignment of the following peaks and bands was used (Brewer et al., 2009; 
Table 1. Physical and chemical characteristics of the biochars derived from different feedstocks: apple tree branch (AB), oak tree (OB), rice husk $(\mathrm{RH})$, and rice straw (RS).

\begin{tabular}{lccccccc}
\hline Samples & $\begin{array}{c}\text { Temperature } \\
\left({ }^{\circ} \mathrm{C}\right)\end{array}$ & $\begin{array}{c}\text { Biochar } \\
\text { yield } \\
(\%)\end{array}$ & $\begin{array}{c}\text { Volatile } \\
\text { content } \\
(\%)\end{array}$ & $\mathrm{pH}\left(\mathrm{H}_{2} \mathrm{O}\right)$ & $\begin{array}{c}\text { Methylene } \\
\text { blue } \\
\left(\mathrm{mgg}^{-1} \mathrm{DW}\right)\end{array}$ & $\begin{array}{c}\mathrm{I}_{2} \\
\text { adsorption } \\
\left(\mathrm{mg} \mathrm{g}^{-1} \mathrm{DW}\right)\end{array}$ & $\begin{array}{c}\text { BET } \\
\text { surface area } \\
\left(\mathrm{m}^{2} \mathrm{~g}^{-1}\right)\end{array}$ \\
\hline $\mathrm{AB}$ & 400 & 28.3 & $32.36 \pm 0.05$ & $7.02 \pm 0.08$ & $4.36 \pm 0.21$ & $44.96 \pm 2.61$ & 11.90 \\
& 500 & 16.7 & $18.27 \pm 0.28$ & $9.64 \pm 0.07$ & $12.04 \pm 0.38$ & $97.87 \pm 2.65$ & 58.60 \\
& 600 & 16.6 & $11.07 \pm 0.20$ & $10.04 \pm 0.02$ & $5.65 \pm 0.39$ & $122.05 \pm 1.53$ & 208.69 \\
& 700 & 15.8 & $7.72 \pm 0.10$ & $10.03 \pm 0.02$ & $10.63 \pm 0.67$ & $208.28 \pm 1.50$ & 418.66 \\
& 800 & 15.5 & $6.82 \pm 0.07$ & $10.02 \pm 0.02$ & $51.79 \pm 0.58$ & $298.51 \pm 1.70$ & 545.43 \\
\hline OB & 400 & 35.8 & $32.06 \pm 0.05$ & $6.43 \pm 0.04$ & $3.90 \pm 0.28$ & $38.66 \pm 0.04$ & 5.60 \\
& 500 & 28.6 & $19.42 \pm 0.27$ & $8.10 \pm 0.12$ & $5.59 \pm 0.47$ & $91.74 \pm 0.06$ & 103.17 \\
& 600 & 22.0 & $12.30 \pm 0.01$ & $8.85 \pm 0.07$ & $5.51 \pm 0.39$ & $131.27 \pm 1.47$ & 288.58 \\
& 700 & 20.0 & $8.28 \pm 0.07$ & $9.54 \pm 0.00$ & $17.06 \pm 0.16$ & $212.79 \pm 0.09$ & 335.61 \\
& 800 & 19.1 & $7.87 \pm 0.06$ & $9.68 \pm 0.03$ & $29.38 \pm 0.47$ & $250.28 \pm 1.40$ & 398.15 \\
\hline $\mathrm{RH}$ & 400 & 48.6 & $22.00 \pm 0.13$ & $6.84 \pm 0.03$ & $2.91 \pm 0.75$ & $44.07 \pm 1.55$ & 193.70 \\
& 500 & 42.4 & $10.56 \pm 0.11$ & $8.99 \pm 0.04$ & $9.72 \pm 0.37$ & $75.38 \pm 1.58$ & 262.00 \\
& 600 & 37.3 & $6.02 \pm 0.27$ & $9.41 \pm 0.00$ & $13.50 \pm 0.21$ & $68.95 \pm 3.13$ & 243.00 \\
& 700 & 32.8 & $3.85 \pm 0.11$ & $9.52 \pm 0.02$ & $13.88 \pm 0.99$ & $121.02 \pm 1.58$ & 256.00 \\
& 800 & 32.0 & $3.17 \pm 0.19$ & $9.62 \pm 0.01$ & $34.06 \pm 0.34$ & $174.40 \pm 3.07$ & 295.57 \\
\hline RS & 400 & 39.3 & $22.42 \pm 0.09$ & $8.62 \pm 0.03$ & $29.32 \pm 2.40$ & $74.66 \pm 2.64$ & 46.60 \\
& 500 & 32.6 & $12.80 \pm 0.11$ & $9.82 \pm 0.01$ & $29.58 \pm 2.81$ & $95.94 \pm 1.52$ & 59.91 \\
& 600 & 23.4 & $8.36 \pm 0.03$ & $10.19 \pm 0.01$ & $33.65 \pm 4.93$ & $85.57 \pm 1.58$ & 129.00 \\
& 700 & 18.4 & $5.33 \pm 0.13$ & $10.39 \pm 0.03$ & $40.45 \pm 3.02$ & $100.55 \pm 1.52$ & 149.00 \\
& 800 & 18.3 & $4.47 \pm 0.15$ & $10.47 \pm 0.04$ & $82.61 \pm 2.02$ & $190.21 \pm 1.31$ & 256.96 \\
\hline
\end{tabular}

Calvero, 2011). The peak around $30 \mathrm{ppm}$ was assigned to the methylenic chains and/or $\mathrm{CH}_{2}$ groups of the various lipid compounds and plant waxes; the two peaks at 55 and $70 \mathrm{ppm}$ were assigned to methoxy and O-alkyl groups, characteristic of relatively easily biodegradable compounds such as cellulose and hemicellulose; the broad band around $130 \mathrm{ppm}$ was assigned to alkyl substitutions in the $p$-hydroxy phenyl ring of the cinnamic and $p$-coumaric units of both lignin and suberin biopolymers as well as to both partially degraded lignin structures and condensed aromatic and olefinic carbons; and the sharp peak at $170 \mathrm{ppm}$ was assigned to the large content of carboxyl groups in the aliphatic acids of plant and microbial origin and/or amide groups in amino acid moieties. The spectra were integrated in the chemical shift (ppm) resonance intervals of 0-45 ppm (paraffinic carbons), 46-65 ppm (methoxy $\mathrm{C}$ from $\mathrm{OCH}_{3}$, and complex aliphatic carbons), 66-90 ppm (O-aliphatic $\mathrm{C}$ such as alcohols and ethers), 91-145 ppm (aromatic carbon), 145-160 ppm (phenolic carbons), 160-185 ppm (carboxyl, amides, and ester), and 185-220 ppm (carbonyls) (Wang et al., 2007; Zhang et al., 2012).

\section{Result and discussion}

\subsection{Biochar physicochemical characteristics}

The characteristics of the biochars derived from different agricultural wastes are shown in Table 1. Low-temperature pyrolysis produced a higher biochar yield and enriched volatile-matter composition than the high-temperature pyrolysis. The biochar yields and volatile contents gradually diminished as the pyrolysis temperature increased. Moreover, the type of feedstock also affected the biochar yields and the volatile-matter content. Among the different biochar types, woody biochars $(\mathrm{AB}$ and $\mathrm{OB}$ ) showed a larger change in the volatile content from 400 to $800^{\circ} \mathrm{C}$ than non-woody biochars (RS and RH), as previously observed (Enders et al., 2012). The high volatile-matter content of woody biochars at relatively low temperatures is due to the presence of lignin in woody feedstocks, which can partially resist pyrolytic decomposition at $400^{\circ} \mathrm{C}$, but not at temperatures as high as $950^{\circ} \mathrm{C}$ (used for the determination of the ash content). The biochars derived from rice material (RS and $\mathrm{RH}$ ) showed a high ash content at all temperature ranges, and this may be the cause of the partial change in the composition promoted by a possible interaction between organic and inorganic constituents during the feedstock pyrolysis in the biochars that contain an amount of ash larger than 20\% (Enders et al., 
Table 2. Elemental composition of the biochars derived from different feedstocks: apple tree branch (AB), oak tree (OB), rice husk (RH), and rice straw (RS).

\begin{tabular}{lccccccc}
\hline Samples & $\begin{array}{c}\text { Temperature } \\
\left({ }^{\circ} \mathrm{C}\right)\end{array}$ & $\mathrm{C}^{*}(\%)$ & $\mathrm{H}^{*}(\%)$ & $\mathrm{N}^{*}(\%)$ & $\mathrm{O}(\%)$ & $\mathrm{O} / \mathrm{C}$ & $\mathrm{H} / \mathrm{C}$ \\
\hline $\mathrm{AB}$ & 400 & $70.18 \pm 0.15$ & $4.13 \pm 0.01$ & $0.76 \pm 0.00$ & $20.56 \pm 0.12$ & 0.22 & 0.71 \\
& 500 & $79.12 \pm 0.00$ & $2.65 \pm 0.09$ & $0.34 \pm 0.01$ & $11.98 \pm 0.10$ & 0.11 & 0.40 \\
& 600 & $81.46 \pm 0.05$ & $1.96 \pm 0.02$ & $0.46 \pm 0.00$ & $13.63 . \pm 0.26$ & 0.12 & 0.29 \\
& 700 & $82.26 \pm 1.39$ & $1.21 \pm 0.05$ & $0.41 \pm 0.02$ & $16.34 \pm 0.68$ & 0.15 & 0.18 \\
& 800 & $84.84 \pm 0.08$ & $0.60 \pm 0.01$ & $0.34 \pm 0.01$ & $5.81 \pm 0.03$ & 0.05 & 0.08 \\
\hline $\mathrm{OB}$ & 400 & $70.52 \pm 0.21$ & $3.70 \pm 0.02$ & $0.69 \pm 0.02$ & $21.47 \pm 0.15$ & 0.23 & 0.63 \\
& 500 & $77.57 \pm 0.31$ & $2.51 \pm 0.16$ & $0.51 \pm 0.03$ & $17.73 \pm 0.45$ & 0.17 & 0.39 \\
& 600 & $81.22 \pm 0.48$ & $1.92 \pm 0.01$ & $0.48 \pm 0.02$ & $15.96 \pm 0.15$ & 0.15 & 0.28 \\
& 700 & $83.22 \pm 0.23$ & $1.16 \pm 0.06$ & $0.31 \pm 0.00$ & $14.97 \pm 0.07$ & 0.13 & 0.17 \\
& 800 & $82.85 \pm 0.42$ & $0.69 \pm 0.06$ & $0.32 \pm 0.00$ & $17.29 \pm 0.12$ & 0.16 & 0.10 \\
\hline $\mathrm{RH}$ & 400 & $44.59 \pm 0.26$ & $2.50 \pm 0.00$ & $0.69 \pm 0.02$ & $16.32 \pm 0.23$ & 0.27 & 0.67 \\
& 500 & $45.15 \pm 0.33$ & $1.27 \pm 0.03$ & $0.47 \pm 0.02$ & $7.12 \pm 0.16$ & 0.12 & 0.34 \\
& 600 & $40.35 \pm 0.74$ & $0.85 \pm 0.05$ & $0.37 \pm 0.01$ & $9.23 \pm 0.31$ & 0.17 & 0.25 \\
& 700 & $38.81 \pm 0.46$ & $0.46 \pm 0.04$ & $0.26 \pm 0.02$ & $12.69 \pm 0.20$ & 0.25 & 0.14 \\
& 800 & $40.41 \pm 0.68$ & $0.28 \pm 0.01$ & $0.22 \pm 0.00$ & $2.69 \pm 0.01$ & 0.05 & 0.08 \\
\hline $\mathrm{RS}$ & 400 & $49.92 \pm 0.15$ & $2.80 \pm 0.12$ & $1.22 \pm 0.01$ & $12.02 \pm 0.06$ & 0.18 & 0.67 \\
& 500 & $37.48 \pm 0.22$ & $0.93 \pm 0.03$ & $0.61 \pm 0.01$ & $8.64 \pm 0.33$ & 0.17 & 0.30 \\
& 600 & $33.78 \pm 1.02$ & $0.60 \pm 0.07$ & $0.41 \pm 0.04$ & $13.68 \pm 0.32$ & 0.30 & 0.21 \\
& 700 & $36.26 \pm 0.79$ & $0.51 \pm 0.06$ & $0.34 \pm 0.02$ & $17.38 \pm 0.94$ & 0.36 & 0.17 \\
& 800 & $29.17 \pm 0.37$ & $0.25 \pm 0.02$ & $0.25 \pm 0.01$ & $3.71 . \pm 0.01$ & 0.10 & 0.10 \\
\hline
\end{tabular}

2012). The elemental composition of the biochars prepared at $800^{\circ} \mathrm{C}$ is shown in Supplement Table 1. Rice plants are rich in $\mathrm{Si}$, which is strongly related to the ash content of the biochar (Mukome et al., 2013). This favors the formation of the $\mathrm{Si}-\mathrm{C}$ bonds, thereby increasing the number of aromatic components and recalcitrance of the biochars as a result of an increase in the pyrolysis temperatures (Guo and Chen, 2014). In the case of woody feedstocks, recalcitrant carbons such as lignin are the main component (Liu and Zhang, 2009; Spokas et al., 2010; Joseph et al., 2013).

The $\mathrm{pH}$ value of biochars increased with temperature, probably as a consequence of the relative concentration of non-pyrolyzed inorganic elements, already present in the original feedstocks (Novak et al., 2009). The porosity and surface area represent the most critical physical properties of biochar for the improvement of soil properties such as soil adsorption capacity and water retention ability (Kalderis et al., 2008). The application of the RH biochar has been reported to enhance these properties (Kalderis et al., 2008; Liu and Zhang, 2009; Lei and Zhang, 2013). As shown in Table 1, a biochar production at higher temperatures generally leads to an increase in the MB number, $\mathrm{I}_{2}$ absorption, and surface area, compared to the production at lower temperatures; this is in line with previous studies (Gaskin et al., 2008; Liu and Zhang, 2009; Yu et al., 2011). In addition, our data showed that the difference in the microporosity $\left(\mathrm{I}_{2}\right)$ between the biochars obtained from wood feedstock $(\mathrm{AB}$ and $\mathrm{OB})$ and those from rice residues (RH and RS) gradually increased as the pyrolysis temperature increased from 500 to $800^{\circ} \mathrm{C}$. In addition, the surface areas of RH and RK diminished at $800^{\circ} \mathrm{C}$, while those of $\mathrm{AB}$ and $\mathrm{OB}$ expanded. The former behavior was attributed to the ash content in the biochar, which filled or blocked the access to micropores, resulting in a relatively low surface area (Mackay and Roberts, 1982; Song and Guo, 2012).

\subsection{Elemental composition of biochars}

Analytical elements and both $\mathrm{H} / \mathrm{C}$ and $\mathrm{O} / \mathrm{C}$ ratios are useful indicators of the character of biochars (Nguyen and Lehmann, 2009). Data in Table 2 suggest that an increase in the temperature results in a larger loss of $\mathrm{H}$ and $\mathrm{O}$ compared to that of $\mathrm{C}$. The dehydrogenation of $\mathrm{CH}_{3}$ as a result of thermal induction indicates a change in the biochar recalcitrance (Harvey et al., 2012). In addition, a biomass material typically comprises labile and recalcitrant $\mathrm{O}$ fractions; the former is rapidly lost after the initial heating, while the latter is retained in the char of the final product (Rutherford et al., 2013).

Because of the high temperature of the charring process, the $\mathrm{H} / \mathrm{C}$ and $\mathrm{O} / \mathrm{C}$ ratios (Table 2) are reduced as a result of dehydration and decarboxylation reactions. The $\mathrm{O} / \mathrm{C}$ ratio in the $400-500^{\circ} \mathrm{C}$ range changed according to the following order: RS $>$ RK $>$ AB $>$ OB. Yang et al. (2007) and Khodadad et al. (2011) found that the biochar derived from wood 

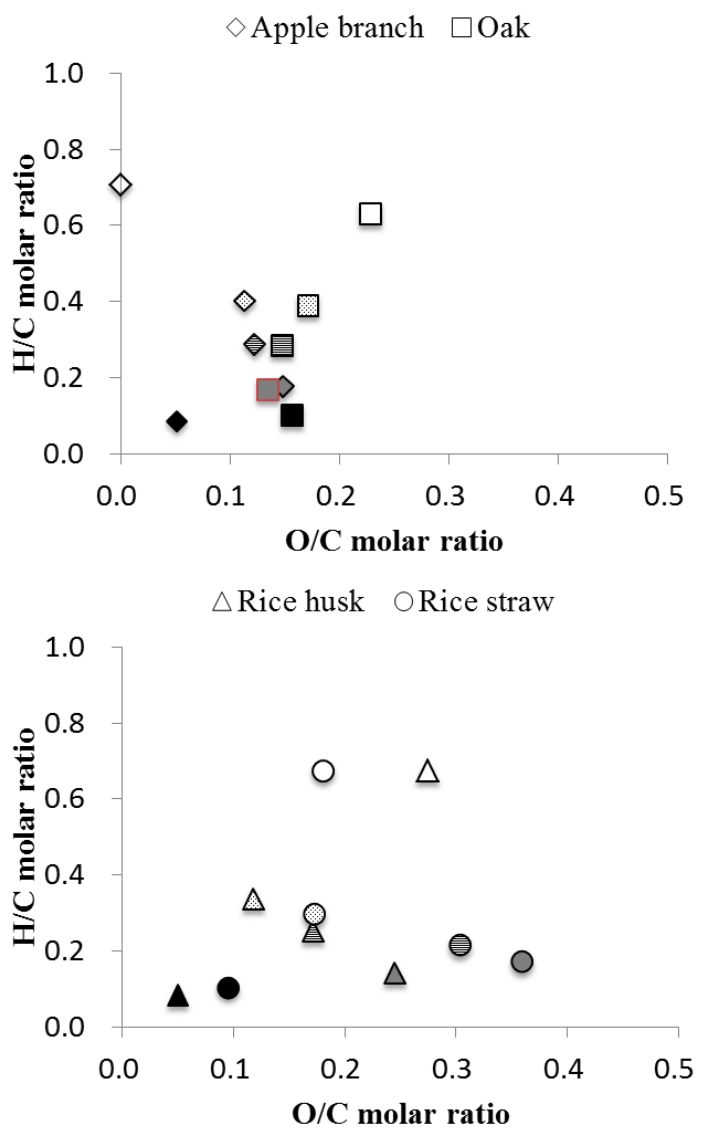

Figure 1. Van Krevelen diagram of the biochars derived from different feedstocks: apple tree branch $(\mathrm{AB})$, oak tree $(\mathrm{OB})$, rice husk $(\mathrm{RH})$, and rice straw (RS). Each symbol indicates the pyrolysis temperature as follows: black: $800^{\circ} \mathrm{C}$; gray: $700{ }^{\circ} \mathrm{C}$; lined: $600^{\circ} \mathrm{C}$; dotted: $500^{\circ} \mathrm{C}$; and white: $400^{\circ} \mathrm{C}$.

at higher temperatures is less biologically labile, because it contains a relatively larger amount of aromatic-organic matter compared to that of biochars prepared from agricultural residues at lower temperatures. As shown in the van Krevelen diagram (Fig. 1), the $\mathrm{H} / \mathrm{C}$ and $\mathrm{O} / \mathrm{C}$ ratios steadily diminish as the temperature increases, reflecting the loss of easily degradable carbon compounds such as volatile matter. Similarly, a lower $\mathrm{C} / \mathrm{O}$ ratio at higher temperatures indicates a structural arrangement of the aromatic rings (Spokas et al., 2010), which form very stable crystal graphite-like structures (Wu et al., 2012; Dong et al., 2013).

A comparison of the feedstocks in the diagram (Fig. 1) indicates that the $\mathrm{H} / \mathrm{C}$ and $\mathrm{O} / \mathrm{C}$ ratios in the $\mathrm{AB}$ and $\mathrm{OB}$ biochars show a stable reduction at 600 and $700{ }^{\circ} \mathrm{C}$, whereas the RS and RH biochars are located in the area of low $\mathrm{H} / \mathrm{C}$ combined with high $\mathrm{O} / \mathrm{C}$, probably attributed to the fact that ash minerals alter their composition through fusion and sintering during pyrolysis (Xiao et al., 2014). The change in the physical and structural composition of the RS biochar obtained at the pyrolysis temperatures of 500 and $700^{\circ} \mathrm{C}$ was reported by Guo and Chen (2014), using Scanning electron microscopy/energy dispersive X-ray spectroscopy (SEM-EDS) analysis. These authors reported that the presence of silicon of the RH biochar obtained at $500^{\circ} \mathrm{C}$ was associated with the carbon and formed a dense carbon structure with Si-encapsulated carbon; in contrast, in the biochars prepared at the temperature of $700^{\circ} \mathrm{C}$ (the highest used in this study), the silicon component was physically distanced from the carbon structure.

\subsection{Thermal analysis}

Thermal analysis is a useful method to study the structure of biochar materials (Kalderis et al., 2014; Mimmo et al., 2014). In this work, all biochar samples showed a similar thermaldegradation profile (Fig. 2), with the weight loss proportionally increasing with the temperature of pyrolysis. In this respect, a clear difference among the feedstocks (wood vs. nonwood) was observed, i.e., the weight loss of $\mathrm{AB}$ and $\mathrm{OB}$ and that of RH and RK was 90 and $40-50 \%$ of the total weight, respectively; this behavior reflects the higher mineral content in rice materials. In addition, the mineral component functions as a barrier that prevents the diffusion of heat and therefore the release of the volatile component during the charring process (Xu and Chen, 2013).

\subsection{Chemical composition with spectra parameters (FT-IR and NMR)}

FT-IR spectroscopy is a great tool to observe the shift change of chemical composition. The aliphatic loss process is represented by the band of FT-IR with aliphatic $\mathrm{C}-\mathrm{H}$ stretching $\left(2950-2850 \mathrm{~cm}^{-1}\right)$ at increasing temperature from 400 to $600{ }^{\circ} \mathrm{C}$ (Figure 2); at the same time, the representative peaks for aromatic carbon appeared more clearly, such as $\mathrm{C}-\mathrm{H}$ stretching (750-900 and $\left.3050-3000 \mathrm{~cm}^{-1}\right), \mathrm{C}=\mathrm{C}\left(1380-1450 \mathrm{~cm}^{-1}\right), \mathrm{C}-\mathrm{C}$, and $\mathrm{C}-\mathrm{O}$ stretching $\left(1580-1700 \mathrm{~cm}^{-1}\right)$. As shown by the infrared spectra, the charring temperature modifies the functional group, and thus aliphatic $\mathrm{C}$ groups decrease but aromatic $\mathrm{C}$ increases (Lee et al., 2010). Since the biochar longevity in relation to its production is still a matter of debate (Nguyen and Lehman, 2009; Peng et al., 2011), the pyrolysis process at $600^{\circ} \mathrm{C}$, which leads to a higher recalcitrant character by increasing the number of aromatic compounds, is a suitable method for carbon sequestration. However, when the charring temperature range is at $700-800^{\circ} \mathrm{C}$, the intensity of the bands such as that of the hydroxyl groups $\left(3200-3400 \mathrm{~cm}^{-1}\right)$ and aromatic groups (1580-1600 and $\left.3050-3000 \mathrm{~cm}^{-1}\right)$ gradually diminishes. Previous studies (Yuan et al., 2011) have shown that the number of bounds representing functional groups are present in biochars obtained at lower temperature $\left(300\right.$ and $\left.500^{\circ} \mathrm{C}\right)$ and are absent in those derived at $700^{\circ} \mathrm{C}$. 

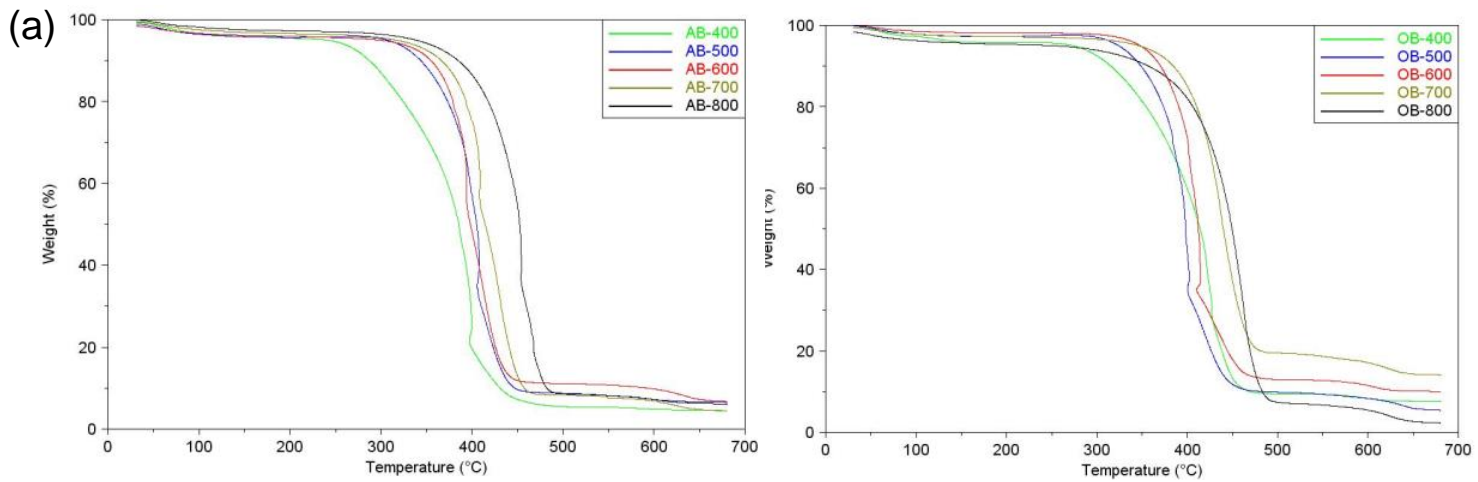

(b)
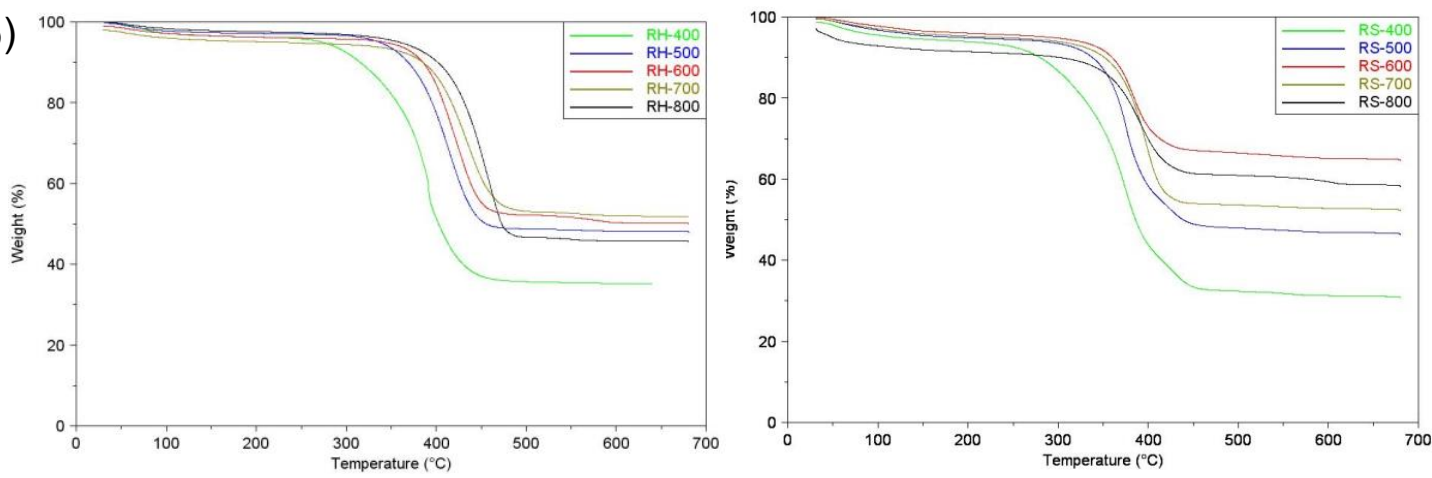

Figure 2. Thermal analysis of the biochars obtained from (a) wood materials (apple tree branch (AB) and oak tree (OB) as well as (b) rice residues (rice husk $(\mathrm{RH})$ and rice straw $(\mathrm{RS})$ ).

The nature of the feedstock was reflected by the presence of bands around 460,800 , and $1040-1100 \mathrm{~cm}^{-1}$, which were assigned to $\mathrm{SiO}_{2}$, and these bands were observed in all the RH and RS biochars (Fig. 3b). In plant physiology, silica is known to be the most critical component for plant phytoliths, as it protects the plant carbon from degradation (Wilding et al., 1969; Parr, 2006). Indeed, $\mathrm{SiO}_{2}$ is a major component in the chemical structure of rice material. The shoulder observed around $1600 \mathrm{~cm}^{-1}$ in the RH and RS biochars, which was assigned to the aromatic compounds, is still present at temperatures as high as $800^{\circ} \mathrm{C}$ during the biochar production. Guo and Chen (2014) proposed a novel silicon-carbon framework that may provide a new perspective for the evaluation of the biochar stability.

The ${ }^{13} \mathrm{C}$ NMR spectra of different biochars (in Fig. 3a and b) show a strong condensed aromatic signal at $127 \mathrm{ppm}$. Furthermore, this signal was observed more clearly in all different biochars which are produced at $600^{\circ} \mathrm{C}$, and the sharpness of this peak was gradually weaken as temperature increased above $600^{\circ} \mathrm{C}$. The shoulder of the methoxyl carbons of lignin and that of carboxylic carbons, at 57 and $190 \mathrm{ppm}$, respectively, also weakened as temperature increased. These signals were imperceptible in the RS biochars obtained at $800^{\circ} \mathrm{C}$ (Fig. 3b), indicating its decomposition during pyrolysis. From this result as well as that shown in the FT-IR fig- ure (Fig. 3), it is worth noting that there is not much need to produce biochar at very high temperature $\left(700-800^{\circ} \mathrm{C}\right)$ in order to preserve stability character, since these temperatures may reduce the amount of functional groups in the structure, limiting the chemical properties of the biochar as soil amendment. Concerning lower temperature, the shoulder observed at around $20 \mathrm{ppm}$, assigned to easily degradable carbon compounds, appeared for the biochars produced at $400^{\circ} \mathrm{C}$; this shoulder was not detected in the biochars produced at $500^{\circ} \mathrm{C}$. This is in agreement with previous studies (McBeath et al., 2013) that have shown that the biochars produced at temperatures of $300-400^{\circ} \mathrm{C}$ exhibit broad alkyl signals and carbohydrate bands; these bands were not detected above $400^{\circ} \mathrm{C}$. As shown in the previous section, the biochars produced at lower temperatures contain a large amount of volatile carbon. This type of easily degradable compound possibly contributes as a substrate and source of $\mathrm{C}$ and energy for soil microorganisms (Khodadad et al., 2011). Thus, a lower temperature may be suitable for the application of the biochars for the improvement of soil fertility. In contrast, higher-temperature pyrolysis selects functional groups and produces a predominantly aromatic presence in chemical composition, consequently resulting in the formation of recalcitrant structure. 

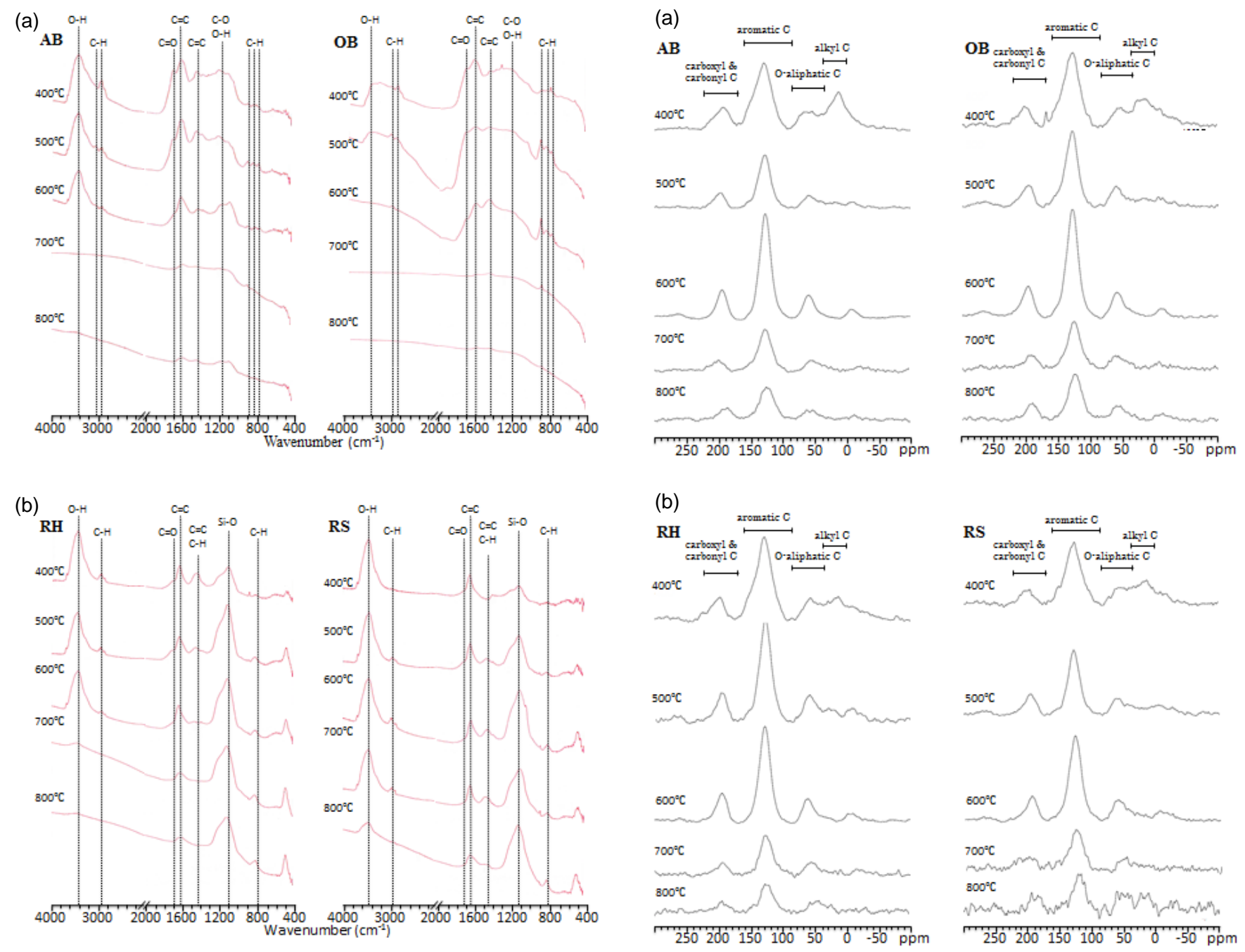

Figure 3. Fourier-transform infrared (FT-IR) spectra of the biochars obtained from (a) wood materials (apple tree branch $(\mathrm{AB})$ and oak tree $(\mathrm{OB})$ as well as $(\mathbf{b})$ rice residues (rice husk $(\mathrm{RH})$ and rice straw (RS)).

Figure 4. Cross-polarization magic angle spinning (CPMAS) ${ }^{13} \mathrm{C}$ nuclear magnetic resonance $\left({ }^{13} \mathrm{C}\right.$-NMR) spectra of the biochars obtained from (a) wood materials (apple tree branch $(\mathrm{AB})$ and oak tree $(\mathrm{OB}))$ as well as (b) rice residues (rice husk $(\mathrm{RH})$ and rice straw (RS)).

\section{Conclusions}

The data presented in this work showed that both the pyrolysis temperature and the type of feedstock strongly influence the physicochemical properties of the biochars. In particular, an increase in the temperature improved the adsorption properties such as surface area, porosity, and recalcitrant chemical character in woody biochars ( $\mathrm{AB}$ and $\mathrm{OB})$. In contrast, ricematerial biochar (RH and $\mathrm{RS}$ ) shows a higher yield during the pyrolysis process than that of $\mathrm{AB}$ and $\mathrm{OB}$. In addition, the properties of the rice-material biochar products are different from woody biochars, i.e., the inorganic components are combined with organic moieties as a consequence of the carbon encapsulation by silicon presence. Finally, higher-heat production (temperatures above $600^{\circ} \mathrm{C}$ ) causes the decomposition of the functional groups through heat degradation.

\section{The Supplement related to this article is available online at doi:10.5194/bg-11-6613-2014-supplement.}

Acknowledgements. This work was partly supported by the bilateral project of the Japan Society for the Promotion of Science (JSPS) and the Spanish National Research Council (CSIC).

Edited by: X. Wang 


\section{References}

Alburquerque, J. A., Salazar, P., Barrón, V., José Torrent, J., Campillo M.C., Gallardo A., and Villar, R.: Enhanced wheat yield by biochar addition under different mineral fertilization levels, Agron. Sustain. Dev., 33, 475-484, 2013

Beesley, L., Moreno-Jiménez, E., Gomez-Eyles, J. L., Harris, E., Robinson, B., and Sizmur, T.: A review of biochars' potential role in the remediation, revegetation and restoration of contaminated soils, Environ. Pollut., 159, 3269-3282, 2011.

Brewer, C. E., Schmidt-Rohr, K., Satrio, J. A., and Brown R. C.: Characterization of biochar from Fast pyrolysis and gasification systems, Environ. Prog. Sustain. Energy, 28, 386-396, 2009.

Cabrera, A., Cox, L., Spokas, K. A., Celis, R., Hermosín, M. C., Cornejo, J., and Koskinen, W. C.: Comparative sorption and leaching study of the herbicides fluometuron and 4chloro-2 methylphenoxyacetic acid (MCPA) in a soil amended with biochars and other sorbents, J. Agri. Food Chem., 14, 12550-12560, 2011.

Calvelo, P. R., Kaal, J., Camps-Arbestain, M., Lorenzo P. R., Aitkenhead, W., Hedley, M., Macias, F., Hindmarsh, J., and Macia-Agullo, J. A.: Contribution to characterisation of biochar to estimate the labile fraction of carbon, Org. Geochem., 42, 1331-1342, 2011.

Chen, B. and Chen, Z.: Sorption of naphthalene and 1-naphthol by biochars of orange peels with different pyrolytic temperatures, Chemosphere, 76, 127-133, 2009.

Dong, X., Ma, L. Q., Zhu, Y., Li, Y., and Gu, B.: Mechanistic nvestigation of mercury sorption by brazilian pepper biochars of different pyrolytic temperatures based on X-ray photoelectron spectroscopy and flow calorimetry, Environ. Sci. Technol., 47, 12156-12164, 2013.

Enders, A., Hanley, K., Whitman, T., Joseph, S., and Lehmann, J.: Characterization of biochars to evaluate recalcitrance and agronomic performance, Bioresource. Technol., 114, 644-653, 2012.

Fellet, G., Marchiol, L., Delle Vedove, G., and, Peressotti, A.: Application of biochar on mine tailings: Effects and perspectives for land reclamation, Chemosphere, 83, 1262-1267, 2011.

Gaskin, J. W., Steiner, C., Harris, K. C., Das, C., and Bibens, B.: Effect of low-temperature pyrolysis conditions on biochar for agricultural use, Transactions of the Asabe, 51, 2061-2069, 2008.

Gaspard, S., Altenor, S., Dawson, E. A., Barnes P. A., and Ouensanga, A.: Activated carbon from vetiver roots: gas and liquid adsorption studies, J. Hazard. Mater., 144, 73-81, 2007.

Guo, J. and Chen, B., Insights on the molecular mechanism for the recalcitrance of biochar: interactive effects of carbon and silicon components. Environ. Sci. Technol. 48, 9103-9101, 2014.

Harvey, O. M., Herbert, B. E., Kuo, L. J., and Louchouarn, P.: Generalized two-dimensional perturbation correlation Infrared spectroscopy reveals mechanisms for the development of surface charge and recalcitrance in plant-derived biochars, Environ. Sci. Technol., 46, 10641-10650, 2012.

Haslinawati, M. M., Matori, K. A., Wahab, Z. A., Sidek, H. A. A., and Zainal, A. T.: Effects of temperature on the ceramic from rice husk ash, Int. J. Basic Appl. Sci., 9, 111-116, 2009.

Joseph, S., Graber, E. R., Chia, C., Munroe, P., Donne, S., Thomas, T., Nielsen, S., Marjo, C., Rutlidge, H., Pan, G. X., Li, L., Taylor, P., Rawal, A., and Hook, J.: Shifting paradigms: development of high-efficiency biochar fertilizers based on nano-structures and soluble components, Carbon Manage., 4, 323-343, 2013.
Kalderis, D., Kotti, M. S., Méndez, A., and Gascó, G.: Characterization of hydrochars produced by hydrothermal carbonization of rice husk, Solid Earth, 5, 477-483, 2014.

Khodadad, C. L. M., Zimmerman, A. R., Uthandi, S., Green. S. J. J., and Foster, J. S.: Taxa-specific changes in soil microbial composition induced by pyrogenic carbon amendments, Soil Biol Biochem., 43, 385-392, 2011.

Knoblauch C. Maarifat A. A. Pfeiffer, E. M., and Haefele S. M.: Degradability of black carbon and its impact on trace gas fluxes and carbon turnover in paddy soils, Soil Biol. Biochem., 43, 1768-1778, 2011.

Lee, J. W., Kidder, M., Evans, B. R., Paik, S., Buchanan, A. C., Garten, C. T., and Brown, R. C.: Characterization of of biochars produced from cornstovers for soil amendment, Environ. Sci. Technol., 44, 7970-7974, 2010.

Lehmann, J.: Bio-energy in the black, Frontiers Ecol. Environ., 5, 381-387, 2007.

Lehmann, J., Rillig, M. C., Thies, J., Masiello, C. A., Hockaday, W. C., and Crowley, D.: Biochar effects on soil biota - A review, Soil Biol. Biochem., 43, 1812-1836, 2011.

Lei, O. and Zhang, R.: Effects of biochars derived from different feedstocks and pyrolysis temperatures on soil physical and hydraulic properties, J. Soil. Sedim., 13, 1561-1572, 2013.

Liu, Z. and Zhang, F. S.: Renoval of lead from water using biochars prepared from hydrothermal liquefaction o biomass, J. Hazard. Mater., 167, 933-939, 2009.

Mackay, D. M. and Roberts, P. V.: The influence of pyrolysis conditions on yield and microporosity of lignocellulosic chars, Carbon, 20, 95-105, 1982.

McBeath, A. V., Smernik, R. J., Krull, E. S., and Lehmann, J.: The influence of feedstock and production temperature on biochar carbon chemistry: A solid-state 13C NMR study, Biomass Bionenerg., 60, 121-129, 2013.

Mimmo, T., Panzacchi, P., Baratieri, M., Davies C. A., and Tonon, G.: Effect of pyrolysis temperature on miscanthus (Miscanthus $\mathrm{x}$ giganteus) biochar physical, chemical and functional properties, Biomass Bioenerg., 62, 149-157, 2014.

Mukherjee, A. and Zimmerman, A.: Organic carbon and nutrient release from a range of laboratory-produced biochars and biocharsoil mixtures, Geoderma, 193, 122-130, 2013.

Mukome, F. N. D., Zhang, X., Silva, L. C. R., Six, J., and Parikh, S. J.: Use of chemical and physical characteristics to investigate trends in biochar feedstocks, J. Agric. Food Chem., 61, 2196-2204, 2013.

Nguyen, B. T. and Lehmann, J.: Black carbon decomposition under varying water regimes, Org. Geochem., 40, 846-853, 2009.

Novak, J. M., Lima, I., Xing, B., Gaskin, J. W., Steiner, C., Das, K. C., Ahmedna, M., Rehrah, D., Watts, D. W., Busscher, W. J., and, Harry, S.: Characterization of designer biochar produced at different temperatures and their effects on a loamy sand, Annals Environ. Sci., 3, 195-206, 2009.

Novak, J. M., Busscher, W. J., Watts, D. W., Laird, D. A., Ahmedna, M. A., and Niandou, M. A. S.: Short-term $\mathrm{CO}_{2}$ mineralization after additions of biochar and switchgrass to a Typic Kaniudult, Geoderma, 154, 281-288, 2010.

Parr, J. F.: Effect of fire on phytolith coloration, Geoarcheology, 21, 171-185, 2006.

Peng, X., Ye, L. L., Wang, C. H., Zhou, H., and Sun, B.: Temperature and duration-depend rice stra-derived biochar: characteris- 
tics and its effects on soil properties of an Untisol in southern China, Soil Tillage Res., 112, 159-166, 2011.

Robertson, S. J., Rutherford, M. P., López-Gutiérrez, J. C., and Massicotte, H. B.: Biochar enhances seedling growth and alters rootvsymbioses and properties of sub-boreal forest soils, Can. J. Soil Sci., 92, 329-340, 2012.

Rutherford, D. W., Wershaw, R. L., Rostad, C. E., and Kelly, C. N.: Effect of formation conditions on biochars: compositional and structural properties of cellulose, lignin, and pine biochars, Biomass Bioenerg., 46, 693-701, 2012.

Singh, B., Singh B. P., and Cowie, A. L.: Characterisation and evaluation of biochars for their applications a soil amendment, Aust. J. Soil Res., 48, 516-525, 2010.

Song, W. and Guo, M.: Quality variations of poultry litter biochar generated at different pyrolysis temperatures., J. Anal. Appl. Pyrol., 94, 138-145, 2011.

Spokas, K. A.: Review of the stability of biochar in soils: predictability of O : C molar ratios, Carbon Manage., 1, 289-303, 2010.

Suri, A. and Horio, M.: Solid biomass combustion, in: Handbook of Combustion vol. 4, Solid Fuels, edited by: Lackner, M., Winter, F., and Agarwal, A. K., WILEY-VCH Verlag GmbH \& Co. KGaA, Weinheim, chapter 3, 85-140, 2010.

Wang, X. L., Cook, R., Tao, S., and Xing, B. S.: Sorption of organic contaminants by biopolymers: Role of polarity, structure and domain spatial arrangement, Chemosphere, 66, 1476-1484, 2007.
Wilding, L. P., Brown, R. E., and Holowaychuk, N.: Asccesibility and properties of occluded carbon in biogenetic opal, Soil Sci., 103, 56-61, 1969.

Wu, W., Yang, M., Feng, Q., McGrouther, K., Wang, H., Lu, H., and Chen, Y.: Chemical characterization of rice straw-derived biochar for soil amendment, Biomass Bioenerg., 47, 268-276, 2012.

Xiao X., Chen B., and Zhu, L.: Transformation, Morphology, and Dissolution of Silicon and Carbon in Rice Straw-Derived Biochars under Different Pyrolytic Temperatures, Environ. Sci. Technol., 48, 3411-3419, 2014.

$\mathrm{Xu}, \mathrm{Y}$. and Chen, B.: Investigation of thermodynamic parametres in the pyrolysis conversion $\mathrm{f}$ biomass and manure to biochars using thermogravimetrisc analysis. Bioresource. Tenhnol., 146, 485-493, 2013.

Yang, H., Yan, R., Chen, H., Lee, D. H., and Zheng, C.G.: Characteristics of hemicellulose, cellulose, and lignin pyrolysis, Fuel, 86, 1781-1788, 2007.

Yu, J. T., Dehkhoda, A. M., and Ellis, N.: Development of biocharbased catalyst for transesterification of canola, Energy fuels 25, 337-344, 2011.

Yuan, J. H., Xu, R. K., and Zhang, H.: The forms of alkalis in the biochar produced from crop residues at different temperatures, Bioresource. Technol., 102, 3488-3497, 2010.

Zhang, G., Zhang, O., Sun, K., Liu, X., Zheng, W., and Zhaoil, Y.: Sorption of simazine to corn straw biochars prepared at different pyrolytic temperatures, Environ. Pollut., 159, 2594-2601, 2011. 